\title{
The Syntax of Slavic Predicate Case
}

\author{
John Frederick Bailyn \\ State University of New York at Stony Brook \\ ibailyn@notes.cc.sunysb.edu
}

In this article I provide a syntactic framework for case patterns found in Slavic secondary predicates, such as those shown in (1).

1) a. Ja

$$
\mathrm{I}_{\mathrm{i}} \text {-Nom found } \text { him }_{\mathrm{k}} \text {-Acc } \text { drunk }_{\mathrm{k}} \text {-Instr }
$$

"I found him drunk."

b. ?Ja našel ego p'janogo

$\mathrm{I}_{\mathrm{i}}$-Nom found him $_{\mathrm{k}}$-Acc drunk $_{\mathrm{k}}$-Acc

"I found him drunk."

Descriptively, the paradigm can be characterized as the alternation between the predicate instrumental (1a) and what I will call "Sameness of case" (1b), but which is commonly known as "agreeing case". "Sameness" or "agreeing case" means the appearance on the predicate of the same case that marks an argument in the sentence, such as the Accusative on drunk in (1b) mathcing the Accusative of the direct object him. The purpose of this article is to show that this variation reduces to the festure makeup of a functional category. In this sense I am supporting a claim made by Rothstein (1992), namely that predication is at its core a syntactic relation, and that thematic and interpretative aspects of it are in a sense secondary, not defining (which is certainly not to say that they do not exist).

Clearly, this view is not shared by all linguists working on predication -- indeed Hinterhoelzl (2000) starts with quite a quite different claim, which I will call the "semantic approach to predicate case choice", given in (2):

2) The semantic approach to predicate case choice (Hinterhoelzl 2000, emphasis mine):

The factors that determine which of the two [predicate case] forms, the agreeing or the invariant form, is appropriate in a given sentence are all semantic in nature.

A similar view is put forth in Kennedy \& Filip (this volume). I will present a particular approach to the syntax of case on predicates which, if it is at all on the right track, will throw the statement in (2) into doubt, at least in its strongest form. Instead, I would like to put forth a different kind of claim, on that could be named "the syntactic approach to predicate case", as given in (3):

3) The syntactic approach to predicate case (this article):

a. The factors that determine which of the two predicate case forms, the agreeing or the invariant form, is possible in a given sentence are all syntactic in nature. 
b. Semantic distinctions are relevant only in those cases where the syntax allows both forms.

(3b) indicates that the two views are not necessarily incompatible, but that (3a) provides possible configurations for the two case patterns, and only in cases where both are syntactically available, does (2) kick in, as stated in (3b). Essentially, I show that there is no more direct connection between the interpretation and the morphology of predicates than there is between the interpretation and morphology of arguments.

The article is structured as follows. In Section 1, I present the Structural Case Hypothesis for predicates, showing that given a few simple assumptions, predicate case should turn out to be a simple analog of argument case, a desired result in an economical theory of language. In section 2 , I present the Slavic data, pointing out along the way cases that appear intractable for semantic approaches such as (2). In section 3, I provide the particular syntactic framework I am assuming, independently motivated for predication in non-Slavic languages. In section 4 , I show how this framework provides an elegant account of the two kinds of Slavic predicate case. Further, I show that only this syntax of predicate case allows a close parallel between argument case and predicate case. In section 5, I address some important additional questions the account raises. In section 6, I conclude with discussion of the compatibility between semantic and syntactic accounts.

\section{The Structural Case Hypothesis for Predicates}

In supporting (3), I will argue for a form of Maling \& Sprouse's (1995) Structural Case Hypothesis for predicates, presented in (4).

4) The Structural Case Hypothesis for Predicates (Maling \& Sprouse 1995)'

a. Predicate NPs always receive case structurally

b. Predicate NPs are assigned structural case in the same way as argument NPs

c. Case "agreement" is epiphenomenal

4) d. Predicate NPs get case via the same mechanism as verbal arguments (this article)

Any theory that requires independent case mechanisms, such as "case by agreement" for handling predicate NPs, in addition to those needed for argument case, is less economical, and should be dispreferred, all else being equal. Such a theory moves morphology and syntax closer together; this possibility serves as the theoretical core of this article. (4d) differs from the 3 specific proposals of Maling \& Sprouse (1995) only in adding the possibility of a kind of Lexical Case for predicates. By showing how predicate NPs get case via the same mechanisms as argument case, we eliminate the necessity for distinct case "strategies" for predicates. With respect to predicates, this obviates the need for thinking of them as "caseless", or not subject to "visibility" in the Government and Binding sense. (Chomsky and Lasnik (1991), den Dikken \& Næss (1993)). ${ }^{2} \quad$ Rather, it allows us to maintain the strong versions of the early GB Case Filter, provided in (5):

5) The Case Filter (Early Government \& Binding (GB) Theory)

$->$ a. Every phonetically realized NP must be assigned (abstract) case (original version)

$->$ b. *NP if NP has phonetic form and no case

(standard version) 
(5) covers all NPs, including predicates, and under Minimalist assumptions, the distinction between arguments and predicates, in terms of case theory, should also not be relevant. As nominals, predicates have particular formal features, associated with the morphology with which they are selected into the Numeration, which must be checked off during the course of a convergent derivation, as discussed in Chomsky (1995):

6) "Generalizing the checking theory, let us assume that, like verbs, nouns are drawn from the lexicon with all of their morphological features, including Case and $\Phi-$ features, and these too must be checked in the appropriate position... This checking too can take place at any stage in a derivation to LF." (Chomsky 1995: 196-197)

I will show that (6) is true in the same way for predicates just as it is true for arguments, that is, that there are instances of structural case on predicates, and there is "Lexical" case -- that is, morphological marking determined by features of a particular lexical item mediated the same way as with argument NPs. Under the system that emerges, "agreement" will indeed turn out to be epiphenomenal, as Maling \& Sprouse claim, and "Sameness" will be seen to result from true structural identity. Thus predicate NPs will indeed turn out to get case via the same mechanisms as verbal arguments, a welcome and probably unavoidable result if the Minimalist case theory is at all on the right track. In the spirit of Maling \& Sprouse, I propose a theory that eliminates recourse to special treatment of predicate case such as "default" case, "case by agreement", or Babby's (1989) "Semantic case" whereby semantic case includes any direct link between the semantics and the morphology, without any syntactic mediation. Indeed, in the course of the discussion we will also see instances in which one or the other pattern is absent for purely structural reasons, where a purely semantic approach would predict them both to be possible. Only in cases where both patterns are possible syntactically do semantic distinctions come in.

\section{$2 \quad$ Slavic Predicate Case}

In the Slavic languages, there are only two case patterns possible on secondary predicates (see Nichols 1973, 1981, Franks 1995, among many others). One pattern is known as the "predicate instrumental", the other I will call "Sameness of case". 3 The two are exemplified in (la-b), repeated as (7) below:

7) Ja $\quad \begin{aligned} & \text { našel ego } \\ & \text { found him }\end{aligned}$-Acc drunk $_{\mathrm{k}}$-Instr
"I found him drunk."

In this section, I provide the relevant patterns for arguments and adjuncts from various Slavic languages. (The distinctions are given in terms of syntactic context -- the reader should see that a purely semantic distinction is probably not directly derivable from the configurational generalizations given here.).

In Russian, primary predicates are marked with "Sameness", whereas all argument secondary predicates and NP adjuncts show Instrumental. Only AP adjuncts allow both. Examples are given in (8), (9-10), (11-12), and (13-14) respectively:

\section{- Russian Primary Predicates: $\quad$ Only "Sameness".}

8) a.Ivan -- durak. *b. Ivan $\quad-$ durakom/duraka...

Ivan-NOM fool-Nom Ivan-NOM fool-Instr/Gen etc.


"Ivan is a fool"
c. Ivan
Ivan-NOM
-- $\operatorname{glup}(y j)$
stupid-Nom
*d. Ivan
Ivan-NOM
-- glupym/glupogo... stupid-Instr/Gen etc.
"Ivan is stupid"

- Russian Secondary Predicate arguments:

Only Instrumental.

9)
a. Ivan
kažetsja glupym.
/ $\quad *$ glup / *glupyj.
Ivan-Nom seems stupid-Instr
stupid-Nom (short or long)
"Ivan seems (to be) stupid."
b. Ivan kažetsja durakom / *durak
Ivan $_{i}$-Nom seems fool ${ }_{i}$-Instr fool ${ }_{i}$-Nom
"Ivan seems (to be) a fool."

10)
a. Ja sčitaju
Ivana
glupym.
/ *glupogo... stupid-Acc
"I consider Ivan stupid."
b. Ja sčitaju Ivana durakom / *duraka... I-Nomconsider Ivan ${ }_{i}$-Acc fool ${ }_{i}$-Instr fool $_{i}$-Acc "I consider Ivan a fool."

- Russian Secondary Predicate NP adjuncts Only Instrumental.

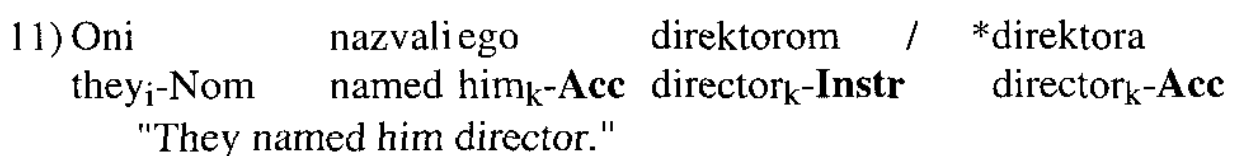

12) On rabotaet vračom $/ *$ vrač

he $_{\mathrm{i}}$-Nom works doctor ${ }_{\mathrm{j}}$-Instr doctor $\mathrm{r}_{\mathrm{j}}$-Nom

"He works as a doctor."

- Russian Secondary Predicate AP adjuncts Both, but "Sameness" restricted.
13) Ja našel ego p'janym / ?p'janogo [both possible] $\mathrm{I}_{\mathrm{i}}$-Nom found himk-Acc drunk $_{\mathrm{k}}$-Instr drunk $_{\mathrm{k}}$-Acc
"I found him drunk."

14) My tancevali golymi / ?golye [both possible] we $_{\mathrm{i}}$-Nom danced nude $_{\mathrm{i}}$-Instr nude $_{\mathrm{i}}-\mathrm{Nom}$

"We danced nude."

In Polish, lexical category is relevant for primary predicates, where we find Instrumental on NPs and "Sameness" on APs, as shown in (15-16):

- Polish Primary Predicates $\quad$ APs $=$ "Sameness", NP = Instrumental.

$\begin{array}{llllll}\text { 15) a. Jan-Nom jest } & \text { głodny-Nom } & * b & \text { Jan-Nom jest } & \text { głodnym-Instr } \\ \text { Jan } & \text { is } & \text { hungry } & & \text { Jan } & \text { is }\end{array}$ 


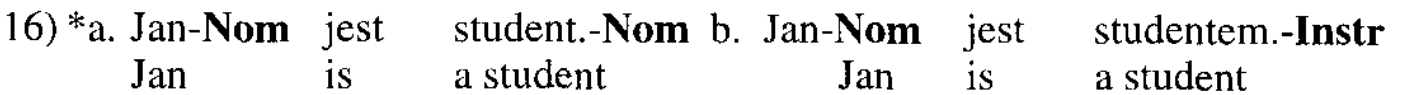

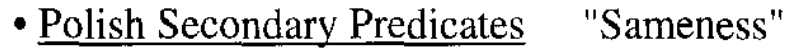

17)
a. Znalazłem
go
pijanego / *pijanym
(POL)
I-found
him-Acc drunk-Acc drunk-Instr
"I found him drunk."

b. Uwazam go za głupca / *głupcem

I-consider him-Acc as fool-Acc fool-Instr

In Serbo-Croatian, the argument/adjunct distinction appears more relevant. Instrumental is lexically selected by verbs such as smatrati ('to consider'), whereas adjuncts show "Sameness". This is shown in (18-19):

- Serbo-Croatian Secondary Predicate arguments: Instrumental (when selected by the verb)

18)a. (Ja) smatram ga budalom $/ *$ budala

I-Nom consider him-Acc a fool-Instr a fool-Acc

"I consider him a fool."

- Serbo-Croatian Secondary Predicate adjuncts:

"Sameness"

19) a. (Ja) plešem go

I-Nom dance-1 sg nude-Nom

"I dance nude." *b. (Ja) plešem golim.

I-Nom dance-1sg nude-Instr

c. Našao sam ga pijanog *d. Našao sam ga pijanim found aux-1sg him-Acc drunk-Acc found aux-1sg him-Acc drunk-Instr "I found him drunk."

Thus we find that there is morphological parametrized variation with respect to the AP vs. NP distinction and the argument/adjunct distinction. Both these patterns of variation alone serve as an initial argument against the Semantic Approach to Predicate Case, in that the meaning of the verb or predicate in question is not directly relevant in determining the case variation. Further, it is clear that identical sentences in different but closely related languages can be marked with distinct morphology, despite having presumably identical semantics. In the next section, I provide the particular theory of predicational syntax that $\mathrm{I}$ assume and that provides a configurational framework for predicate case checking.

\section{The Syntax of Predication}

There are two major directions in the syntax of predication within the generative tradition, summarized in (20):

20) a. The Specifier Hypothesis (Stowell 1981, Koopman and Sportiche 1991)

i) The surface subject in MC predication originates universally in [Spec, V] (and raises)

ii) The surface subject in SC predication originates universally in [Spec, L] ( $L=L e x C a t)$ 
b. The Functional Category Hypothesis (Chomsky 1995, Bowers 1993, Laurençot 1995, Stowell 1995)

i) In MC predication, the surface subject originates in a functional category outside minimal VP

ii) In SC predication, the surface subject originates in a functional category outside minimal LP

In this article, I will argue for a particular version of (20b), The Functional Category Hypothesis, namely that in which predication is directly represented by a functional category Pred(ication)P, as argued for extensively in Bowers 1993, 1997. Major characteristics of this theory are provided in $(21)$ :

21) a. There exists a functional category PredP (PrP) for every instance of "predication"

b. Every $\mathrm{I}^{0}$ selects PredP (primary predication), some V's select PredP (secondary predication).

c. $\operatorname{Pred}^{0}$ selects any lexical category as its complement; structurally, the traditional "predicate" is the Pred ${ }^{0}$ complement.

d. Small clauses are PredP's, either selected (arguments) or adjoined (adjuncts).

e. Argument small clauses are raising structures.

r. Adjunct small clauses are control structures.

Examples of primary and secondary instances of PredP are given in (22):

22) a. I saw John in the kitchen.

b. I consider John a fool.

c. I saw John singing the blues.

d. I consider John crazy.
$\operatorname{Pr}^{0} 1$ selects $\mathrm{VP}, \operatorname{Pr}^{0} 2$ selects $\mathrm{PP}$

$\operatorname{Pr}^{0} 1$ selects $\mathrm{VP}, \operatorname{Pr}^{0} 2$ selects NP

$\operatorname{Pr}^{0} 1$ selects VP, $\operatorname{Pr}^{0} 2$ selects VP

$\operatorname{Pr}^{0} 1$ selects $\mathrm{VP}, \operatorname{Pr}^{0} 2$ selects AP

The structure of I consider John crazy is given in (23):

a. [IP I consider [PrP John [Pr' [Pr e ][AP crazy] ] ] ] (Bowers 1993:595) $=(9 \mathrm{~d})$

b. Structure of $(23 a)^{4}$

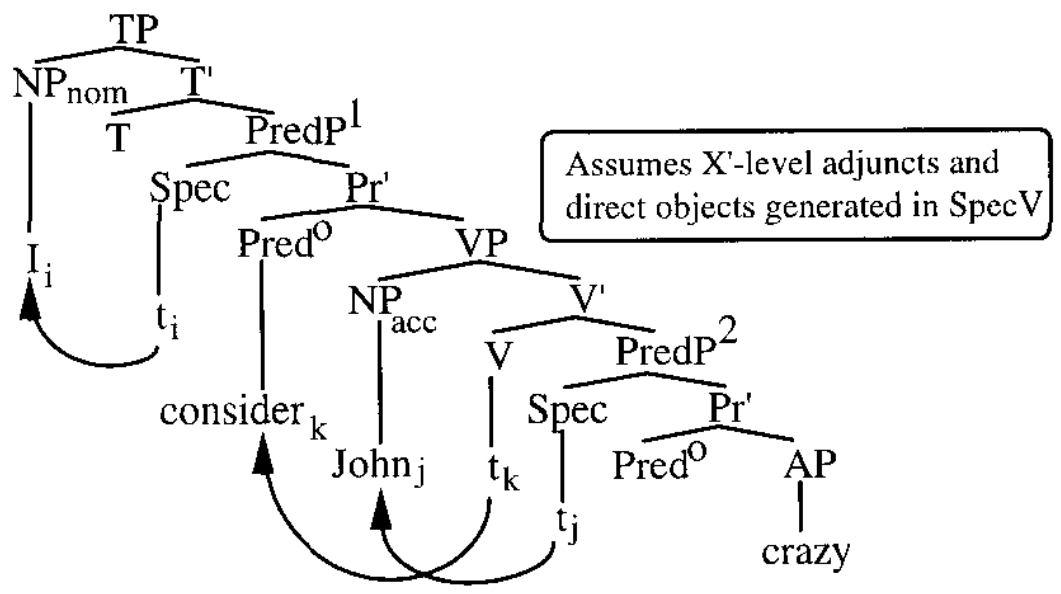

It is beyond the scope of this article to provide a full justification for this approach to predication. However, a short discussion of its principle advantages other than those concerning Slavic predicate case are in order. To begin with, the PredP approach, first presented in Chomsky (1957), provides a particular syntactic configuration for the semantic 
notion of predication. Second, it maintains both crucial aspects of the VP Internal Subject Hypothesis and a uniform X'-theory. Third, it allows for complex internal structure of predicates, as shown in (24):

24) I consider [PredP Fred [DP a mensch] / [DP the best person for the job] / [DPMary's worst enemy] ].

Fourth, it accounts for the exceptional ability of predicates to allow conjunction of (apparently) unlike categories, such as those shown in (25):
a. I consider
Jim [AP crazy]] and
[DP a fool]
b. I consider Jim [AP shrewd] and [pp in the know]

Under the PredP approach, (25) is represented as (26), immediately providing a constituency solution for (25), whereby it is in fact two PredPs that are conjoined, not two unlike categories:
a. I consider $\operatorname{Jim}_{i}$
[PrP $\mathrm{t}_{\mathrm{i}}[\mathrm{AP}$ Crazy]] and
$\left[\mathrm{PrP}_{\mathrm{i}} \quad[\mathrm{DP}\right.$ a fool] $]$
b. I consider $\operatorname{Jim}_{\mathbf{i}}$
[PrP $t_{i}[$ AP shrewd]
and
[PrP $\mathrm{t} \quad[\mathrm{pP}$ in the know]

Further, the PredP approach allows unergatives vs. unaccusatives to be distinguished structurally, provides the necessary number of adverb positions and provides for a reasonable classification for elements such as English as (see Bowers 1997 and Bailyn (forthcoming) for discussion). For our purposes, however, the most important advantage of the Bowers hypothesis is one not discussed in the original work at all, namely that it allows an elegant functional category account of case checking on predicates that is otherwise unavailable without additional stipulation. It is to that analysis that we now turn.

\section{The Syntax of Slavic Predicate Case}

The essential proposal of this section is that the two kinds of predicate case, Instrumental and "Sameness", correspond to the two familiar kinds of argument case: Lexical case and structural case respectively. Given the structures provided above under the PredP theory, these two case mechanisms can be implemented without any additional stipulations, thus supporting the direction of Maling \& Sprouse (1995).

\subsection{Lexically determined Predicate Case (Instrumental)}

Typically, Lexical case on arguments is taken to differ from structural case in that it depends crucially on idiosyncratic case assignment properties of a particular head, usually a verb or preposition, whose exact case requirements must be stated in the lexicon (that is, they cannot be derived from the structure alone). Examples of Lexical case on prepositional and verbal arguments from Russian are given in (26). Violations are shown in (27).

26) Lexical case on arguments:

Prepositions
a. k Ivanu
to Ivan-Dat
b. zavidovat'
to envy
Ivanu
Ivan-Dat
c. u Ivana
d. bojat'sja
Ivana

\section{$\underline{\text { Verbs }}$}



at Ivan-Gen
to fear
Ivan-Gen
$\begin{array}{lll}\text { e. } & \text { Ivanom } \\ \text { with } & \text { Ivan-Instr }\end{array}$
f. interesovat'sja Ivanom
to be interested in Ivan-Instr

27) Lexical case violations (cf. 26)):
$\mathrm{k} \quad$ *Ivane $/ *$ Ivana
/ *Ivanom
to Ivan-Prep / Ivan-Gen / Ivan-Instr

My claim is that the Instrumental case marking on Slavic predicates is similar -- it results from particular properties of the $\operatorname{Pred}^{0}$ head itself, and cannot be directly derived from the configuration in which the predicate is located. Before turning to the exact mechanisms, however, it is necessary to take a look at how Lexical case might work under minimalist assumptions. Here I will maintain a view that is derived from its Government and Binding counterpart, and requires a minor revision of a basic assumption of the minimalist checking theory, without which Lexical and structural case cannot be adequately distinguished.

Recall that under GB theory, Lexical case involved direct case assignment under government to the complement of a theta-assigning head. Such a situation is sketched in (28).

28) Lexical case assignment (under GB theory):<smiles>c1cncnc1</smiles>

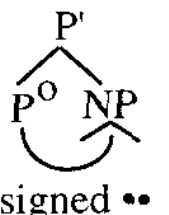

(particular case assigned depends on the $\mathrm{V}$ or $\mathrm{P}$ )

In (29), I present the Predicate Instrumental Rule, based on work by Bailyn \& Rubin (1991), which assumed exactly a Lexical case assignment structure. ${ }^{5}$ The GB version of Lexical Predicate Case is given in (29), from Bailyn \& Rubin (1991):

\section{9) Predicate Instrumental Rule "Rule I" (Russian)}

\section{Pred ${ }^{0}$ assigns Instrumental Case to its complement}

30) Schematic view of Instrumental case assignment under GB theory

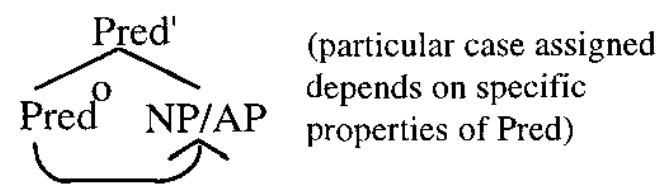

-• Slavic: Instrumental case assigned ••

Within Minimalism, Lexical Case has not been treated in a uniform fashion (although see Lasnik (1999) for relevant discussion.) The usual view of (structural) case checking as being the result of a Spec-Head relation cannot account for Lexical case because it cannot allow for the association with theta-role assignment, and because there is little evidence of raising of lexically-marked arguments into a higher specifier position. Thus Bailyn \& Citko (1998) maintain the spirit of Bailyn \& Rubin (1991) by introducing for such cases Check-on-Merge and the Complement Checking Domain as shown in (31a-b):

31) Lexical case checking (under Minimalism): 
a. Check-on-Merge (Bailyn \& Citko 1998)

Strong Inherent Case features must be checked on Merge

b. The Complement Checking Domain:

i. General Schema

ii. Argument Case
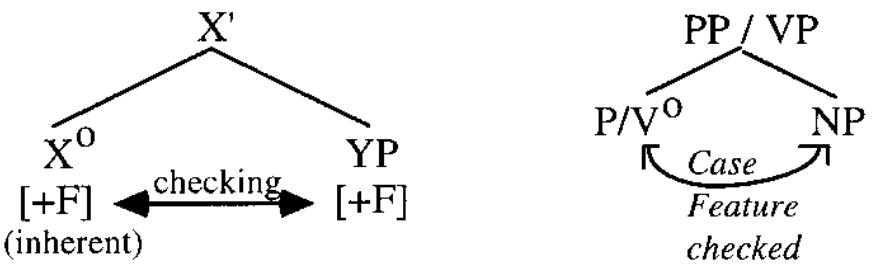

(replaces lexical case assignment)

Given (31), which I assume to be independently necessary to maintain the tight connection in argument case between Lexical case assignment and theta-role assignment, (30) can now be simply restated as (32):

32) Predicate Instrumental Case Checking (replaces (30))

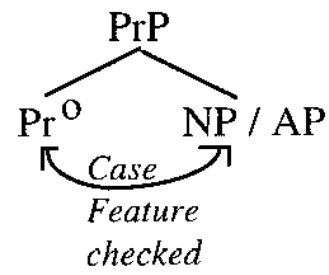

Examples of the workings of (32) are found in sentences such as (33):

33)
a. Saša
kažetsja [PredP $t_{i}$
durakom]
Sasha-Nom seems
fool-Instr
"Sasha seems to be a fool."
b. Ja sčitaju ego ${ }_{j} \quad$ [PredP $t_{i}$ durakom]
I consider him-Acc fool-Instr

"I consider him a fool"

In (33a), the subject of the small clause PredP raises to main clause Nominative case position, where it gets (checks) Nominative case. A tree structure, taken from Bailyn and Rubin 1991, is given in (34): 
34) Structure of Russian argument small clause in (33a):

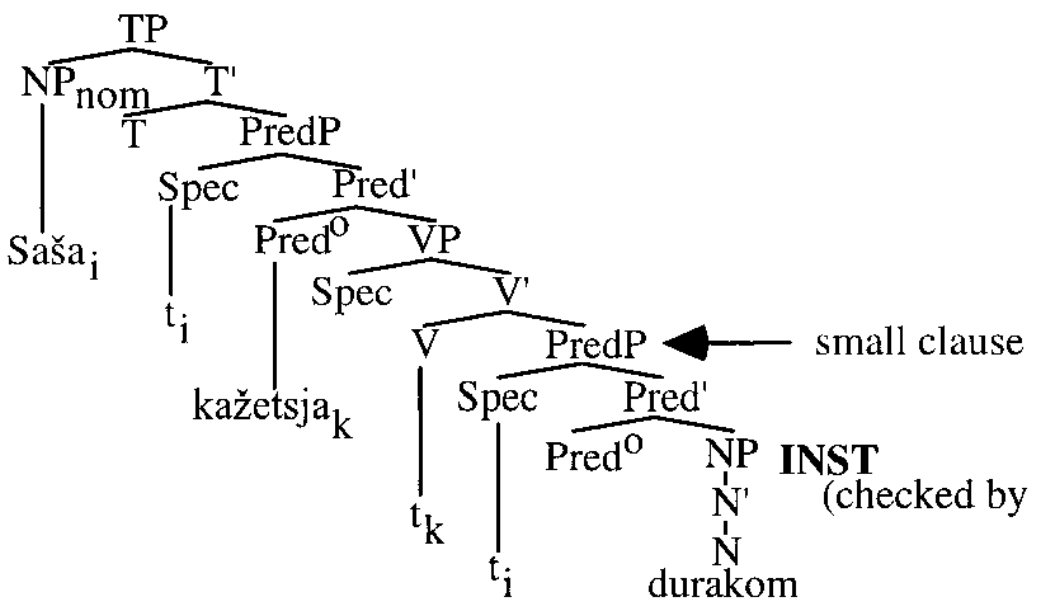

Sasha seems a fool

(33b) shows another instance of a selected PredP whose subject raises for case, this time to object position. I follow Larson (1988) and Bowers (1993) in assuming that Accusative objects are generated in (or raised to) SpecV, whereas lexically-marked objects are in the complement checking domain as shown above.

Adjunct small clauses can also show Instrumental case, as shown in (35a-c).

35)
a. $\mathrm{My}_{\mathrm{i}}$
tancevali
[PredP PRO
golymi.]
we-Nom danced
nude-Instr

"We danced nude."
b. Jel'cina $a_{i} \quad$ vybrali [PredP $P O_{i}$ prezidentom]
Yeltsin-Acc elected-3pl president-Instr
"They elected Yeltsin president"
c. Ja našel ego ${ }_{k} \quad$ [PredP $\mathrm{PRO}_{\mathrm{k}}$ p'janym
$\mathrm{I}_{\mathrm{i}}$-Nom found him $_{\mathrm{k}}$-Acc drunk-Instr
"I found him drunk."

In these cases, the subject of the PredP secondary predicate is large PRO, whose reference is determined by control, theory in the standard fashion. (35a) exemplifies an adjunct small clause controlled by the subject and (35b-c) ones controlled by the direct object. The structure of $(35 \mathrm{c})$ is given in (36): 
36) Structure of (35c) (=(1b))

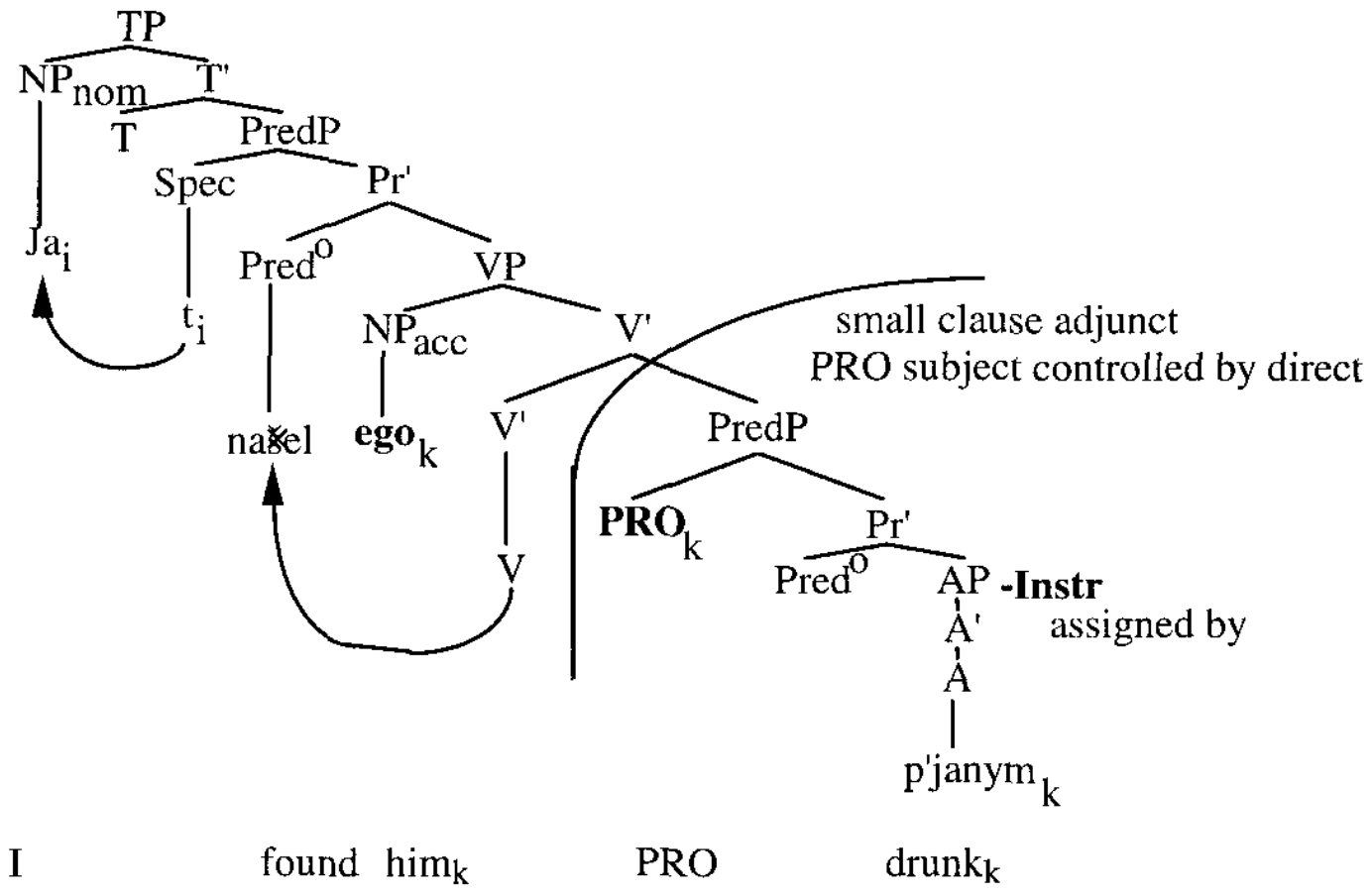

Further, I assume a theory of control that meets the Minimal Distance Principle (MDP):

37) Minimal Distance Principle:

$P R O$ is controlled by the nearest c-commanding potential antecedent

I also assume, following Bowers (1993), that adjuncts are adjoined at the X'-level. Secondary PredP adjuncts are therefore adjoined to $\mathrm{V}^{\prime}$. Given the placement of direct objects in SpecV and oblique objects in the complement position, this approach predicts the impossibility of Instrumental small clauses with oblique controllers, a prediction that is strongly borne out by the facts, as shown in (38):

38)
a. Boris
sovetoval
Saše
golym
Boris ${ }_{i}-$ Nom advised
Sasha $_{k}$-Dat nude $_{i} / *_{k}$-Instr
(??golomu)
"Boris advised Sasha nude." (Boris = nude)

b. Boris pozvonil Saše golym.

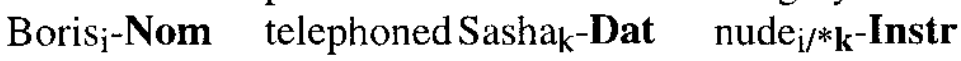

"Boris telephoned Sasha nude." (Boris = nude)
c. Boris bojitsja Saši golym.
Boris ${ }_{j}$-Nom fears Sasha $k_{k}-G e n$ nude ${ }_{i} / *_{k}$-Instr
"Boris fears Sasha nude." (Boris = nude)
d. Boris posmotrel na Sašu golym.
Boris $\mathrm{j}_{\mathrm{i}}$-Nom looked at Sasha $\mathrm{k}_{\mathbf{k}}$-Acc nude $_{\mathrm{i} / \mathbf{k}}$-Instr

"Boris looked at Sasha nude." (Boris = nude)

Comparing the tree in (36) with (38a-d), we see that whereas in (36) the controller of PRO is the internal argument, in (38a-d) it cannot be. This falls out from the structures assumed because (36) containsa direct object, whereas the arguments in (38a-d), all being lexically case marked, are never in high enough position to control the PRO subject of the PredP 
adjunct, adjoined at $\mathrm{V}^{\prime}$. The problem is demonstrated in (39), in which the Dative argument does not c-command the PRO subject of the adjunct PredP.

39) Structure of (38a)

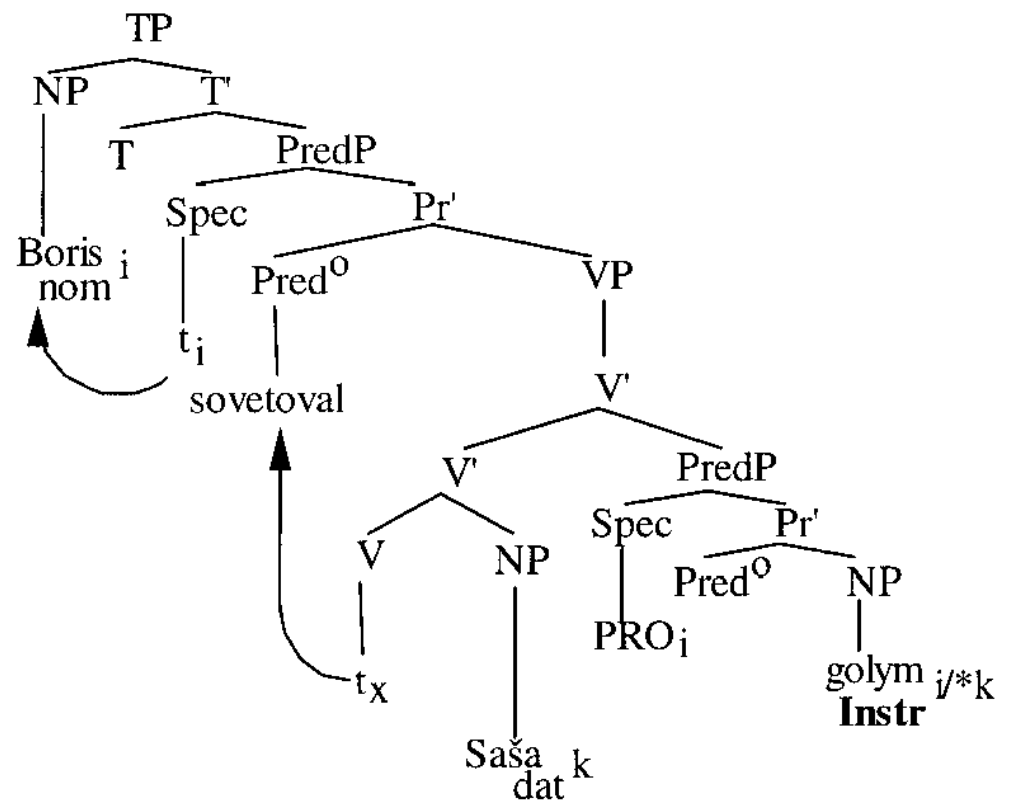

* Boris-Nom advised Sasha-Dat nude-Instr

Thus (39) demonstrates that the configurations proposed account for the lack of oblique controllers, something the semantic Approach to Predicate Case cannot do, at least in the form currently given. Thus the account of Instrumental case on predicates as Lexical case provides further evidence for the Syntactic Approach to Predicate Case. In the next section, we turn to the "Sameness" cases, and show that these correlate with instances of structural argument case, thus further strengthening the syntactic approach.

\subsection{Structurally determined Predicate Case}

Given the framework provided above, we are now in a position to provide a useful account of the cases in which the predicate shows the same case as a structurally marked argument in the sentence. First, recall that these occur in certain languages in exactly the same sentences in which Russian shows Instrumental. This is shown in (19), repeated as (40) below, from Serbo-Croatian

$\begin{array}{cll}\text { a.(Ja) } & \text { plešem go } & \text { go } \\ \text { I-Nom } & \text { dance-1sg } & \text { nude-Nom }\end{array}$

"I dance nude."

c.Našao sam ga pijanog

found aux-1sg him-Acc drunk-Acc

"I found him drunk." *b. (Ja) plešem golim.

I-Nom dance-1 $1 \mathrm{sg}$ nude-Instr

*d. Našao sam ga pijanim found aux-1sg him-Acc drunk-Instr

(40a) and (40c) show occurrences of "Sameness" in PredP adjuncts, controlled by the nominative subject and the accusative direct object respectively. The impossibility of (40b) and (40d) with Instrumental predicates demonstrates that the situation is quite different from Russian, in which Instrumental is preferred but "Sameness" is also possible (we return to this distinction below). Given Minimalist assumptions about language variation, we expect the distinction between the two languages to reduce to a difference in the feature makeup of the Pred $^{0}$ head itself. We have seen that in Russian the Pred head is marked with inherent [+Instr] feature that is checked against the Instrumentally-marked NP or AP predicate in its 
complement position. Clearly, the same Pred head in Serbo-Croatian is lacking in this Instrumental feature, or indeed any inherent case feature. In its absence, the actual case occurrence depends on the structure. Specifically, in the absence of a case-checking Pred ${ }^{0}$ head, the NP or AP predicate must raise into a(n already existing) case position to have its case checked. Thus these nominals raise to get case. ${ }^{6}$ "Sameness" marking on predicates parallels structural case marking on arguments. The general situation is summarized in (41)

41) The typology of non-Instrumental predicate case

Structural Case results from there being no case feature on the relevant Pred 0 The relevant mechanisms,based on Bailyn \& Citko (1998), require no additional stipulations: If Pred $^{0}$ has no case feature, its complement has no source of case in its base position and must raise to structural case position to check case. Assuming the existence of double layered specifier (Chomsky 1995, Koizumi 1995), schematized in (42), we can see the source of the structural case marking in "Sameness" cases: ${ }^{7}$

42) Double layered specifiers (Koizumi 1995, p. 138)

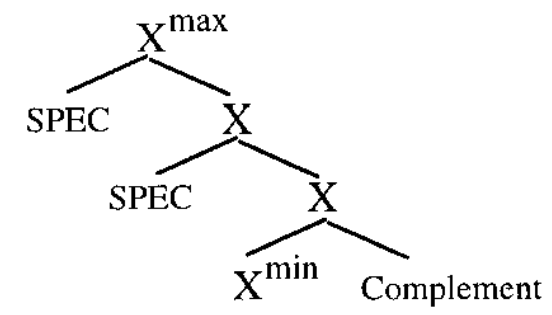

In (42), both the predicate NP and the argument NP check case against the relevant functional category. This is exactly what we find in "Sameness" predicate marking, now clearly analyzable as a form of structural case. The general schema for such cases is shown in (43):

43) LF Configuration for Structural Case on Predicates:

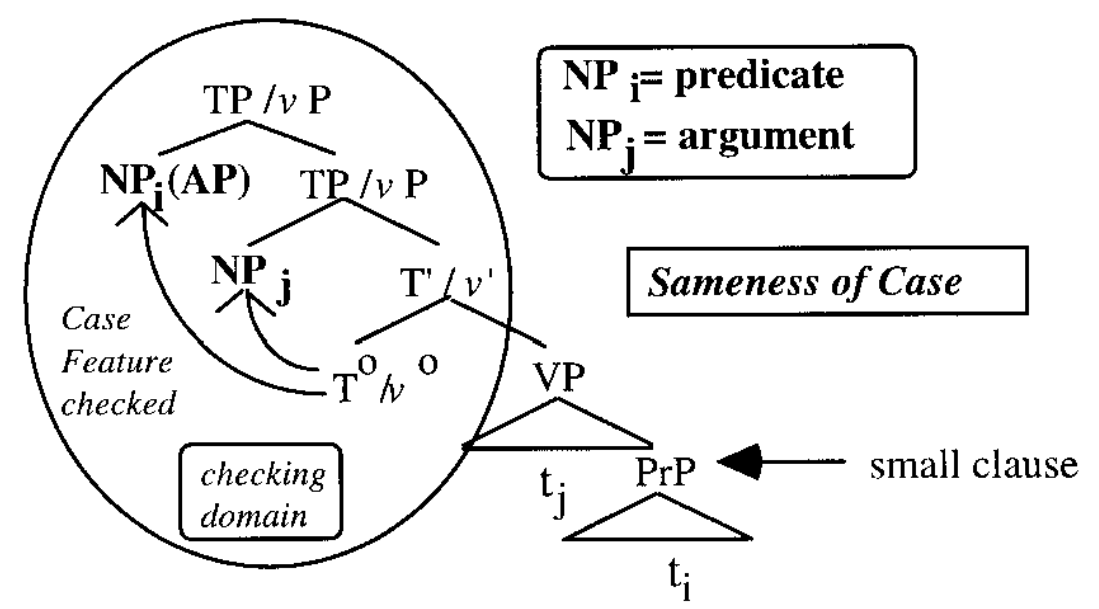

LF movement of the uncased Predicate occurs to the closest structural case checking position, producing the "Sameness" of Case effects, and limiting them to structural case. The relevant portion of the LF structure of (40c) is given in (44): 
44) LF Structure of the Accusative checking domain of (40c):

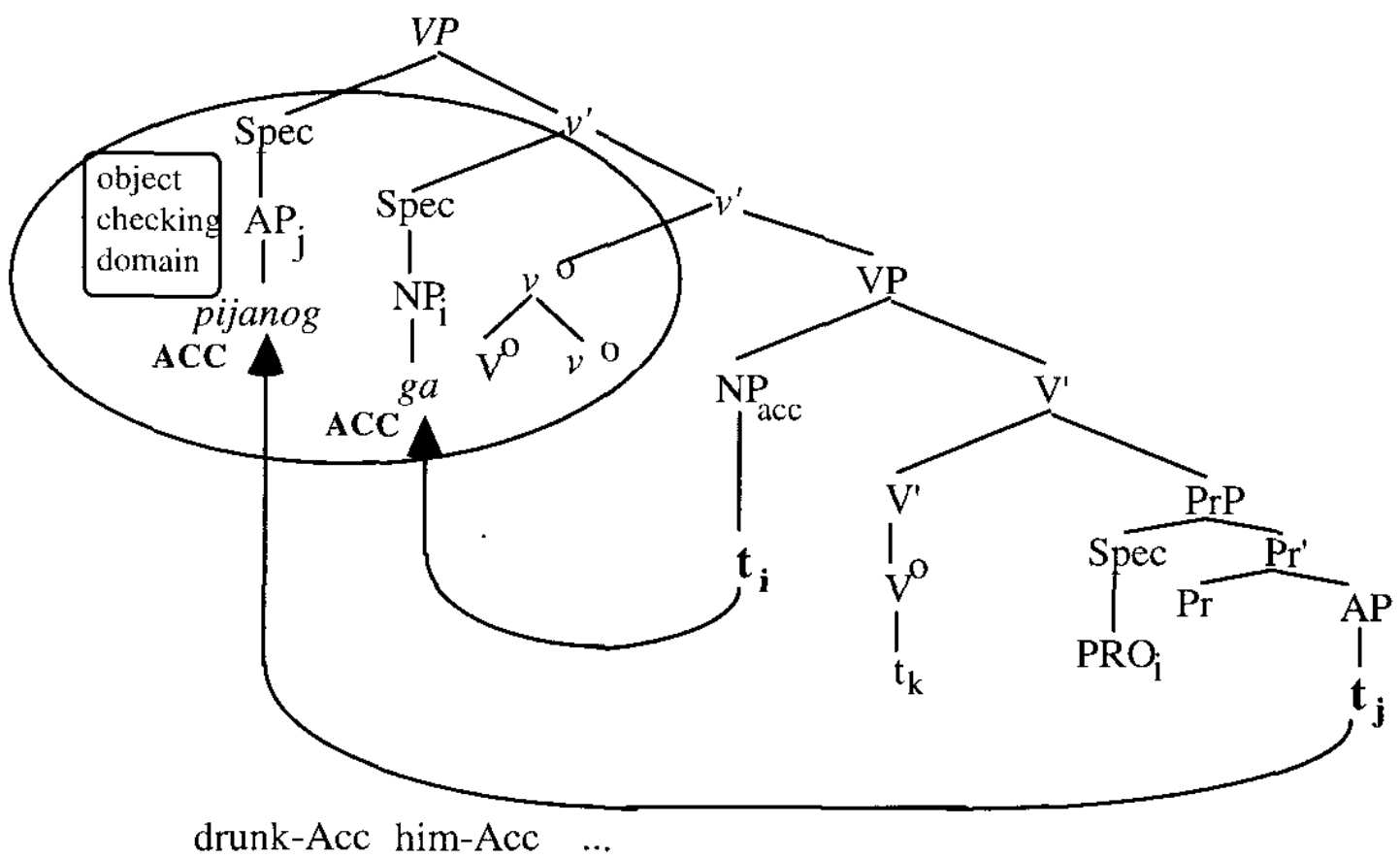

We can now reduce the morphological difference between Serbo-Croatian and Russian small clause predicates to a typological difference in the feature make-up in the Pred ${ }^{0}$ head. A schematic version of the feature makeup of Pred is shown in (45):

45)

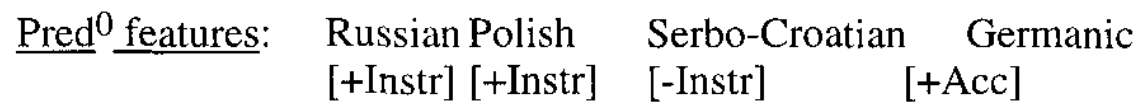

\section{$5 \quad$ Extensions}

As presented, the analysis here provides a syntactic framework under Minimalism for maintaining the spirit of the Maling \& Sprouse 1995 approach to predicate case. Under this approach, predicate case occurrences mirror argument case even more exactly than previously proposed, in that we have instances of both Lexically and Structural case, just as we do for arguments. Furthermore, all Lexical case occurrence are checked in complement position of a Lexical case assignor. All Structural case occurrences are checked in a Spec-Head configuration. Thus the general picture of the syntax of case is simplified by its extension to predicates.

We now have purely syntactic accounts of the paradigms given above -- the presence or absence of a strong inherent case feature on $\operatorname{Pred}^{0}$ determinies whether an invariant inherent case will be assigned, such as the Slavic Instrumental, or whether "Sameness" results from a structural case doubling process when $\operatorname{Pred}^{0}$ cannot check case. The impossibility of "Sameness" in Russian argument small clauses is accounted for by the selectional properties of verbs like consider which select PredP complements whose heads must check Instrumental.

However, various questions are raised by the analysis above that warrant further discussion. These questions are listed in (46): 
46) Questions about the PredP account of predicate case:

I. Why do overt instances of Pred disallow Instrumental case?

II. Why does Russian primary predication not show Instrumental case?

III. How do we account for the Polish AP/NP distinction in copular sentences?

IV. How do we account for "Sameness" on Russian small clause APs such as (1b)?

In the next section, we present brief answers to these important questions. (For more discussion, see Bailyn \& Rubin (1991), Bailyn \& Citko (1998), and Bailyn (forthcoming)).

\subsection{Overt predicators}

In Bailyn (forthcoming) I use the same framework presented here in analyzing the status of certain pieces of morphology in Slavic as overt heads of the PredP functional category. Standard examples of these elements, from Russian, are given in the (b) sentences of $(47-48)$ :

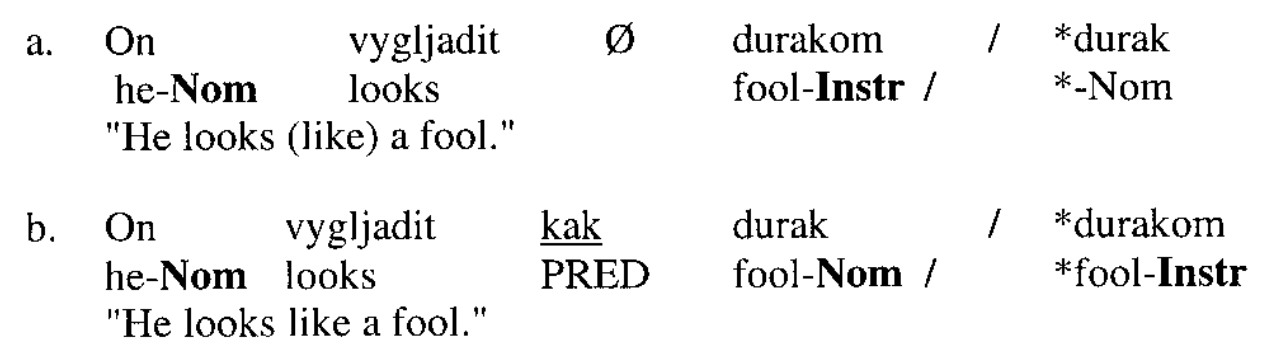 we consider him-Acc
"We consider him (as) one of us."
a. My sčitaem ego $\varnothing$
svoim / * * svoego self's-Instr/ *-Acc
b. My sčitaem ego $\underline{\mathrm{kak}}$ svoego / *svoim we consider him-Acc PRED self's-Acc / *-Instr
"We consider him (as) one of us."

In (47a), we see an NP predicate marked with Instrumental case, checked in a standard Lexical case configuration with a Pred head that has Instrumental case features, as expected in Russian. (47b), on the other hand, has the element $k a k$, analyzed in Bailyn as the head of PredP. Similarly, in (48), when $k a k$ is present, Instrumental on the predicate AP becomes impossible where it is otherwise required. Indeed, it is well-known that Instrumental is always impossible whenever an element such as $k a k$ fills the Pred ${ }^{0}$ head. I draw on ideas of Bowers (1993) for English and Bailyn \& Citko (1998) in showing that the presence of such elements precludes Instrumental case. I adopt the Morphological Pred Rule of Bailyn \& Citko (1998), given in (49):

Morphological Pred Rule (MPR): (from Bailyn \& Citko 1998)

Overt morphology in Pred $^{0}$ absorbs Instrumental Case

(49) has the status of a descriptive generalization, similar to the generalization that passive verbs cannot assign Accusative case. When an NP is generated as the direct object of a passive verb, it must move to get case, which is exactly what happens when an NP or AP predicate is generated as the complement of a filled Pred. The structure of (48b) would then be something like (50): 
50) Structure of (48b)

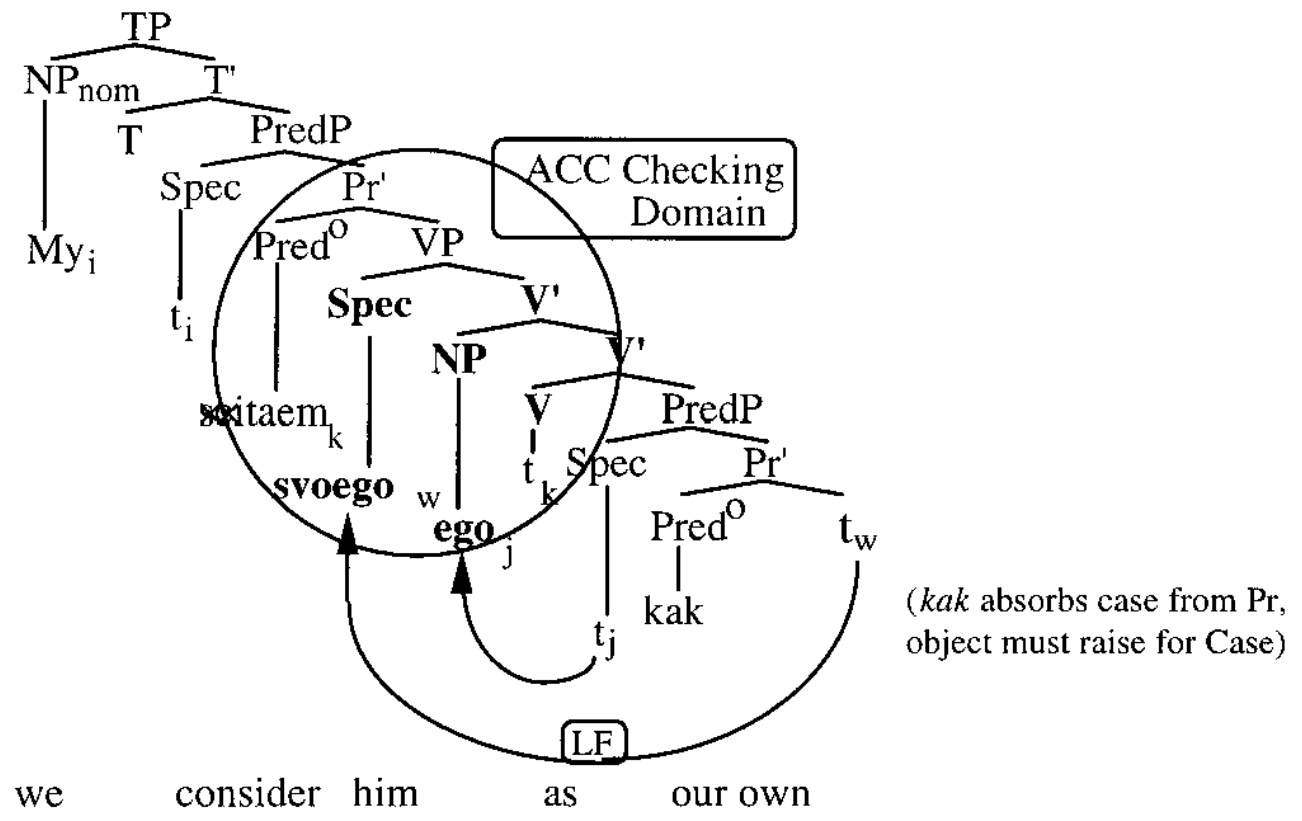

The case absorption hypothesis accounts for the impossibility of overt predicators cooccurring with Instrumental predicates. It is not clear how this regular alternation would be handled in other frameworks.

\subsection{Primary Predicates}

In primary predication in Slavic (Russian and Polish), we find a second occurrence of Nominative, rather than Instrumental on the NP or AP predicate. This is shown in (51):

51) a. Boris byl muzykant. (R)
Boris-Nom was musician-Nom

"Boris was a musician (in his very nature).
b. Jan jest głodny
Jan-Nomis hungry-Nom
"Jan is hungry"
c. Jan to student.
Jan-Nom? student-Nom
"Jan is a student."

These constructions are analyzed in Bailyn (1995) for Russian and in Bailyn \& Citko (1998) for Polish as instantiating verbless structures where the 'to be' element occupies the head of (primary) PredP. In these cases, therefore, to be also serves as an overt predicator. These cases crucially do not involve secondary predication, and as a result have a highly equative meaning. ${ }^{8}$ The surface and LF structures of (51b) are given in (52): 
52) a. Surface (spell-out) structure of (51b) Jan jest glodny "Jan is hungry."

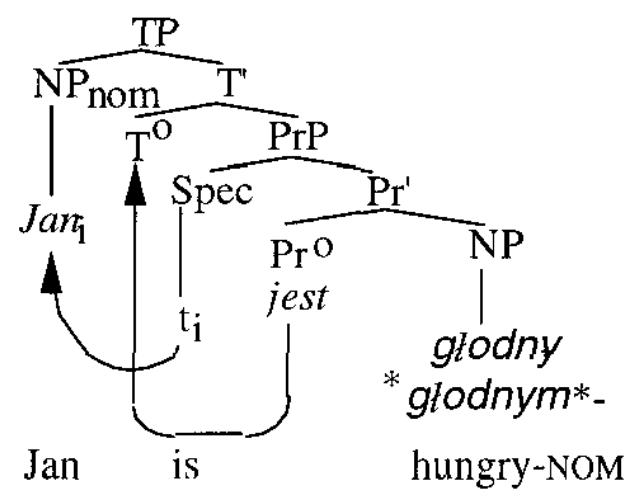

b. LF structure of (51b) Jan jest głodny "Jan is hungry."

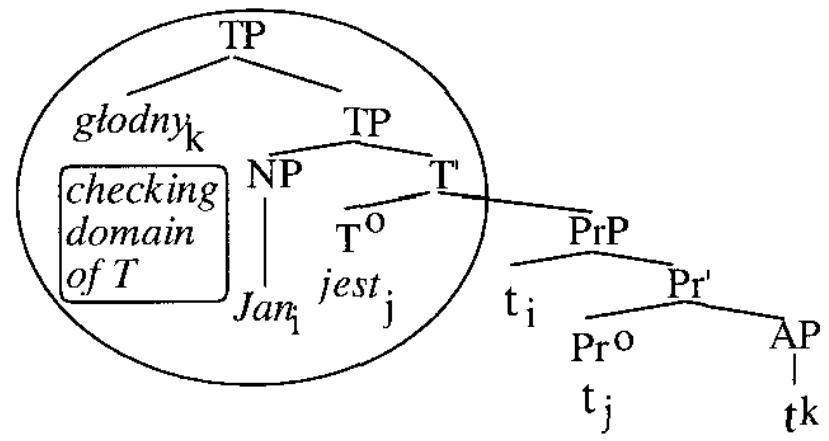

We now can extend the analysis of Polish to to constructions like $(5 \mathrm{lc})$ thus explaiing both its category and the required double Nominative case marking as another example of "Sameness" arising from the effect of an overt predicator.

There remains the issue of Russian present tense double nominatives ('Ivan -- student') which have no overt form of to be. Following previous work (Bailyn \& Rubin 1991, Bailyn 1995, Bailyn \& Citko 1998), I assume that these too are non-verbal sentences, similar in structure to (52), with an overt predicator (the verb to be) whose present tense form happens to be (morphologically) null. However, from the point of view of this article, this is still an overt predicator, simply one that is null on the surface. In this sense, the head of primary $\mathrm{Pred}^{0}$ is filled, simply the morphological form is zero. This differs from secondary predicates where there is nothing in the head of Pred (except the strong Instrumental case features). This appears at first glance to be something of a non-natural class (overt morphology like kak or null copular morphology). However, in both cases we have material relevant to an interface, $\mathrm{PF}$ and LF respectively. Only in cases where there are no interface-interpetable features (such as null secondary $\operatorname{Pred}^{0}$ ), can the Instrumental case feature be carried. ${ }^{9}$ For more discussion see Bailyn \& Citko (1998) and Bailyn (forthcoming).

\subsection{Polish copular sentences}

Recall that in Polish present tense copular sentences with jest ('is'), AP predicates and NP predicates show a morphological distinction, shown in (50).

$$
\begin{array}{llll}
\text { a.Jan jest } & \text { studentem } & / & *_{\text {-student }} \\
\text { Jan -Nom is } & \text { student-Instr } & / & *_{-N o m} \\
\text { "Jan is hungry" } & & \\
\text { b. Jan jest } & \text { glodny } & / & *_{\text {glodnym }} \\
\text { Jan -Nom is } & \text { hungry-Nom } & / & *_{- \text {Instr }} \\
\text { "Jan is hungry" } &
\end{array}
$$


In (53a) we see that NP predicates must be marked Instrumental whereas (53b) shows that AP predicates must be marked Nominative ("Sameness"), as analyzed above. This restriction on Polish jest constructions can be reduced to a selectional restriction on the overt predicator: jest only takes AP complements. The other overt predicator in Polish, to, is the oppsoite: it only takes NP complements. ${ }^{10}$ Thus (53a) involves secondary predication, and an occurrence of jest as a raising verb, and as such is essentially identical to the Russian raising verb schematized in (34) above.

\section{$5.4 \quad$ Russian "Sameness" without overt predicators}

Finally, we are in a position to return to the alternation we began with in (1), repeated as (54) below, in which Russian adjunct small clauses appear to allow both Instrumental and "Sameness".

$$
\begin{aligned}
& \text { a. Ja našel ego p'janym } \\
& \mathrm{I}_{\mathrm{i}} \text {-Nom found } \text { him }_{\mathrm{k}} \text {-Acc drunk } \mathrm{k}_{\mathrm{k}} \text {-Instr } \\
& \text { "I found him drunk." }
\end{aligned}
$$

$$
\begin{aligned}
& \text { b. ?Ja našel ego } \quad \text { p'janogo } \\
& \mathrm{I}_{\mathrm{i}} \text {-Nom found } \text { himm }_{\mathrm{k}} \text {-Acc drunk } \mathrm{k}_{\mathrm{k}} \text {-Acc } \\
& \text { "I found him drunk." }
\end{aligned}
$$

Further, these are the cases that involve a semantic distinction between the two case alternations, discussed in Hinterhoelzl (this volume) and Kennedy \& Filip (this volume). Given the analysis of Russian predicative case presented above, there are two possibilities that can account for (54b). First, we could analyze (54b) as structurally identical with (54a), but with some kind of defective case assignor in the head of PredP (that is, a Pred ${ }^{0}$ head that for whatever reasons fails to have the strong inherent Instrumental case feature that characterizes all other Russian secondary predicates.) This is essentially the approach taken in Bailyn \& Citko (1998). For this to go through, however, we would need to ensure that PredP whose heads have this defective character could never be selected as the complement of raising verbs such as consider or seem, which in Russian only allow Instrumental complements, as we have seen. Secondary predicates showing "Sameness" in Russian occur only with overt morphology. Since it would be difficult to claim that in (54b) Pred is "overt", when there is no morphology present, nor any LF-relevant features, it appears that an analysis with identical structures in (54a) and (54b) is difficult to maintain. This leads us to the other possibility, namely that in $(54 \mathrm{~b})$ there is simply no PredP structure at all. If we allow for the possibility of true "appositive" adjuncts, we would predict that in the absence of a Pred head, the only possible source of case for the predicate would involve LF raising into the specifier of a case checking head, and hence a "Sameness" effect. Such a small clause would look much like the small clauses proposed by Stowell, which would constitute examples of the Lexical Case Hypothesis for small clauses, in these cases only. Thus the structure of (54b) would look something like (55): 
55) Structure of $(54 b)(=(1 b))$

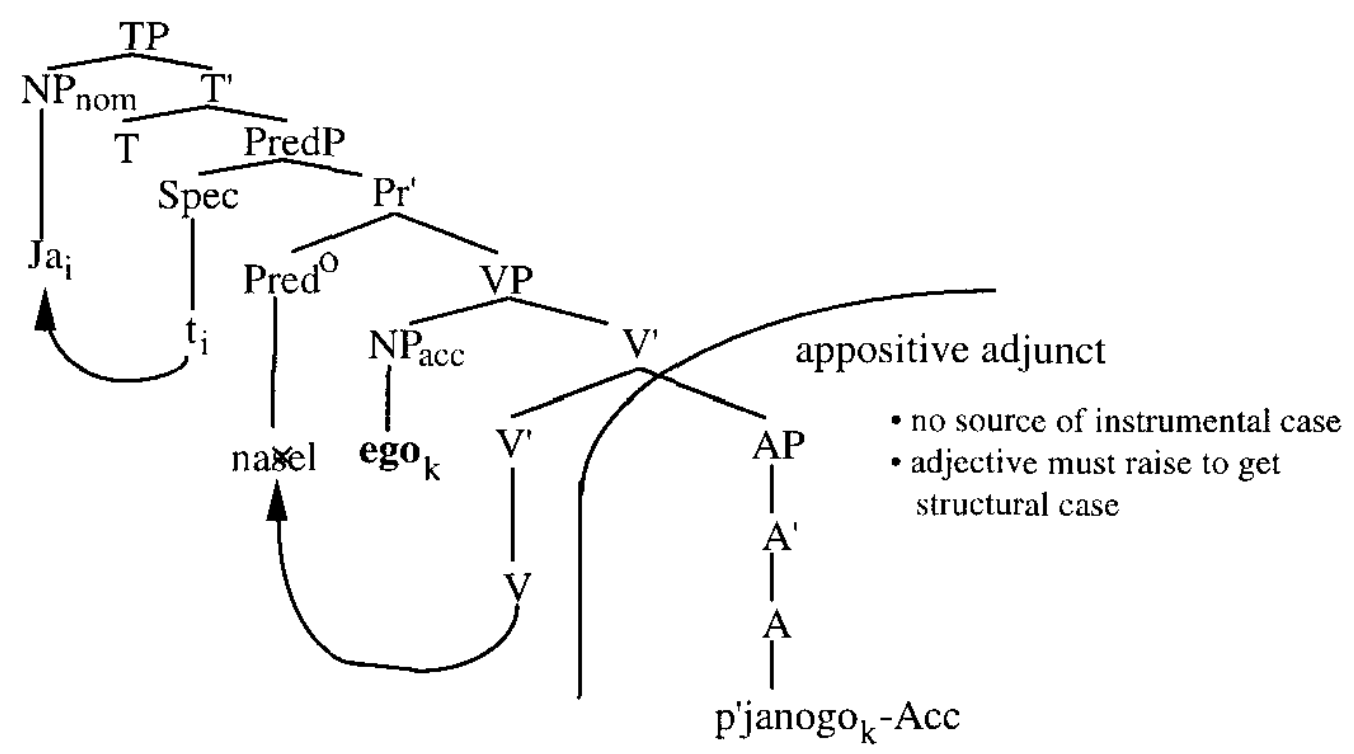

There are three arguments in favor of the appositive approach taken here over that of the defective Pred ${ }^{0}$ head approach suggested in Bailyn \& Citko (1998). First, it explains why the alternation between Instrumental and "Sameness" in Russian is possible only in adjunct cases; in argument small clauses the categorial status of the verbal complement is determined by selectional requirements of the verb (consider requires a PredP complement) and an appositive "Sameness" structure is impossible. Second, it predicts the existence of a semantic distinction between a true secondary predicate, with a full PredP structure, and the appositive small clauses of the type shown in (55). This provides a structural basis for the distinction discussed under the Semantic Approach to Predicative Case. Because this only occurs in adjunct position, it allows us a syntactic characterization of the situations in which the semantic distinction discussed in the other papers in this volume can operate, and provides for those accounts a structural correlation. In this sense, the account suggested here solves a potential problem for the Semantic Approach to Predicative Case choice, namely how to explain why a distinction in the meanings between the Russian options (1a) and (1b), holds here, but does not obtain with respect to the cross-linguistic distinction in cases such as Russian (1a) and its Serbo-Croatian equivalent (36b) which have exactly the same interpretation. In fact, if this article is on the right track, the semantic distinction does not depend on Instrumental vs. "Sameness" but reduces to PredP structures vs. bare appositivestyle small clauses. Third, the appositive account predicts that "Sameness" should be possible in cases where control theory disallows Instrumental case, namely in cases where the small clause predicate refers to an oblique/lexically marked argument of the main verb. Recall (38a), repeated below, in which Instrumental secondary predication referring to the Dative argument were impossible because of control theory.

$\begin{array}{lllll}\text { 38) a. Boris } & \text { sovetoval } & \text { Saše } & \text { golym } & \text { (??golomu) } \\ \text { Boris }{ }_{j}-\text { Nom } & \text { advised } & \text { Sasha }{ }_{k} \text {-Dat } & \text { nude }_{\mathbf{i}} /{ }^{*} \mathbf{k}^{-I n s t r} & \text { nude }_{\mathrm{k}}-\text { Dat }\end{array}$

"Boris advised Sasha nude."

Notice, however, that a Dative "Sameness"-marked AP is marginally possible in this structure. This is expected only if c-command is not relevant for the structures involved. golomu is in the Complement Checking Domain of sovetoval which is responsible for the Dative case marking. Thus the appositive account can allow for such cases, whereas for the PredP account of "Sameness" in Russian, such cases constitute a serious problem. For these three reasons, I maintain that (55) is the proper analysis for ( $1 \mathrm{~b})$, and leave a characterization of the semantic distinction to the other papers in this volume. 
In this article we have seen that a syntactic approach to the case alternations in Slavic predicates is fruitful in characterization the configurations that the different case patterns occur in. This approach is shown to have various advantages. For one thing, cross-linguistic variation reduces to the feature makeup of functional categories, as expected given Minimalist assumptions. Second, it allows us to eliminate any recourse to special case assignment mechanisms for predicative case, as well as any need for semantic case as something distinct from Lexical or structural case. In particular, predicative Instrumental requires the same mechanisms as other instances of inherent or Lexical case, and "Sameness" of Case on predicates reduces to structural case, given the possibility of a predicate and an argument sharing the specifier positions of a single case checking head. Further, we can maintain the usual view within generative grammar that the relation between semantics and morphology is mediated by configuration, and does not constitute a direct correlation. At the same time, the configurations proposed are rich enough to allow distinct structures to correlate with the semantic distinctions in those instances where both forms can occur. Finally, the account moves us one step closer to a strong theory of Case under Minimalism, under which all nominals would fall under one unified Minimalist Case Filter (MCF), along the lines of that proposed by Bailyn \& Citko (1998), given in (56).

\section{6) The Minimalist Case Filter (MCF):}

a. Every $[+\mathrm{N}]$ category must bear formal case features

b. Morphological case is a direct reflection of formal case features

The conclusions of this article allows us to extend the MCF neatly to predicates, not always covered by theta-theory driven versions of the Case Filter under GB Theory. It remains now only to provide distinct configurational checking mechanisms for adjunct (bare) NP adverbs, and we can unite all nominals under a case filter such as (56), increasing the simplicity of the grammar of natural language.

John Frederick Bailyn

Department of Linguistics

SUNY at Stony Brook

Stony Brook, NY 11794-4376

jbailyn@notes.cc.sunysb.edu

\section{References}

Babby, L. (1991) "Non-Canonical Case Assignment Strategies," in Cornell Working Papers in

Linguistics 9, Department of Modern Languages and Linguistics, Cornell University.

Babby, L. and R. Brecht (1975) "The Syntax of Voice in Russian" Language

Bailyn, J. (1995) A Configurational Approach to Russian 'Free' Word Order Doctoral Dissertation, Cornell University.

Bailyn, J. (1998) "Modern Syntactic Theory and the History of the Slavic Languages" in A. Timberlake, ed. American Contributions to the 12 th International Congress of Slavists, Slavica.

Bailyn, J. (forthcoming) "Overt Predicators" Journal of Slavic Linguistics

Bailyn, J. (in preparation) "Rich Morphological Case and Syntactic Structure" Talk given at the German Linguistics Society annual meeting in Leipzig, Germany, March 1, 2001.

Bailyn, J. and B. Citko (1998) "The Morphology of Slavic Predicates" Proceedings of FASL VII, Michigan Slavic Publications.

Bailyn, J. and E. Rubin (1991) "The Unification of Instrumental Case Assignment in Russian" Cornell Working Papers in Linguistics 9. 
Bowers, J. (1993) "The Syntax of Predication" Linguistic Inquiry 24, 591-656.

Bowers, J. (19397) "Predication" Handbook of Linguistics

Brecht, R. and J. Levine (eds) (1986) Case in Slavic, Slavica, Columbus, Ohio.

Cardinalletti, A. and M. Guasti (eds) Small Clauses (Syntax and Semantics vol. 28) Academic Press.

Chomsky, N. (1957) Syntactic Structures The Hague: Mouton.

Chomsky, N. (1995) The Minimalist Program MIT Press.

Chomsky, N (1998) Minimalist Inquiries. MIT Occasional Papers in Linguistics.

Chvany, C. (1975) On the Syntax of BE-sentences in Russian, Slavica, Cambridge, Mass.

Citko, B. (2000) "On the Syntax and Semantics of Polish Adjunct Clauses" ms, SUNY, Stony Brook.

Collins, C. (1997) Local Economy MIT Press

den Dikken, M. \& A Næss (1993) "Case Dependencies: The Case of Predicate Inversion" The Linguistic Review 10: 303-336.

Fowler, G. (1997) "Toward a Rapprochement between Form and Intuition: Approaches to the Russian Double Nominative" M. Lindeth ed., Formal Approaches to Slavic Linguistics, Michigan Slavic Pubs.

Franks, S (1995) Parameters of Slavic Morphosyntax, Oxford University Press.

Gueron, J. \& T. Hoekstra (1995) "The Temporal Interpretation of Predication" In Cardinaletti \& Guasti (eds), $77-108$.

Heycock, C. (1995) "The Internal Structure of Small Clauses" Proceedings of NELS 25.

Hinterhoelzl, R. (2000), "Semantic Coinstraints On case-Agreement in Russian Adjectival Secondary Predicates", paper given at eh Berlin Worksops on the Semantics of Predication, Zentrum für allgemeine Sprachwissenschaft, Berlin, October, 2000.

Kamynina, A. A. (1973) "Upotreblenii vtorogo imenitel'nogo imen sus, “c, estvitel'nyx v sovremennom russkom jazyke," in Russkij jazyk $v$ s, "kole.

Koizumi, M. (1995) Phrase Structure in Minimalist Syntax, Ph.D. Dissertation, MIT.

Koopman, H. and D. Sportiche (1991) "The Position of Subjects" Lingua 85, 211-258.

Koster, J. (1994) "Predicate Incorporation and the Word Order of Dutch" in Paths Towards Universal Grammar G. Cinque et. al. (eds), Georgetown University Press.

Larson, Richard. 1988. "On the double object construction" Linguistic Inquiry 19: 335-392.

Lasnik, Howard. 1999. Minimalist Analysis. Oxford: Blackwell.

Laurençot, E. (1994) "On Infinitives, Agreement, and the Null Case Hypothesis" ms, University of Connecticut, Storrs, CT.

Maling, J. and R. Sprouse (1995) "Structural Case, Specifier-Head Relations, and the Case of Predicate NPs" in H. Haider et al, eds., Studies in Comparative Germanic Syntax, Kluwer, 167-168.

Moro, A. (1995) "Small Clauses with Predicative Nominals" In Cardinaletti \& Guasti (eds), 109-126.

Nichols, J. (1973) The Balto-Slavic Predicate Instrumental: A Problem in Diachronic Syntax, Ph.D Dissertation, University of California, Berkeley.

Nichols, J. (1981) Predicate Nominals: A Partial Surface Syntax of Russian, U California Press, Berkeley.

Patakova, O. V. (1929) "K istorii razvitija tvoritel'nogo predikativnogo v russkom literaturnom jazyke" Slavia VIII: $1-37$.

Pesetsky, D. (1982) Paths and Categories, Ph.D dissertation, MIT.

Przepiórkowski, A. (2000) "Case and Agreement in Slavic Predicates"

Rappaport, G. (1986) "On the Grammar of Simile: Case and Configuration" In Brecht and Levine, eds. Case in Slavic, Columbus, OH: Slavica, 244-280.

Rothstein, S. (1992) "Predication and the Structure of Clauses" Belgian Journal of Linguistics 7, $153-169$.

Rothstein, S. (1995) "Small Clauses and Copular Constructions" In Cardinaletti \& Guasti (eds), 27-48.

Stowell, T. (1989) "Subjects, Specifiers, and X-Bar Theory" in M. Baltin and A. Kroch (eds) Alternative Approaches to Phrase Structure, University of Chicago Press, Chicago, Illinois, 232-262.

Stowell, T. (1991) "Small Clause Restructuring" in R. Freidin (ed) Principles and Parameters in Comparative Grammar, MIT Press, Cambridge, MA.

Stowell, T. (1995) "Remarks on Clause Structure" In Cardinaletti \& Guasti (eds), 271-286.

Svedova, N. (ed.) (1980) Russkaja Grammatika vol. 2, Academy of Sciences, Nauka, Moscow.

Williams, E. (1975) "Small Clauses in English," in J. Kimball, ed., Syntax and Semantics, vol. 4, Academic Press.

Williams, E. (1983) "Against Small Clauses," Linguistic Inquiry 14: 203-238.

Williams, E. (1980) "Predication," Linguistic Inquiry 11: 203-238. 


\section{NOTES}

${ }^{\mathrm{t}}$ Maling \& Sprouse limit their discussion to Germanic, and do not make a distinction between two kinds of case patterns. However their account is crucial in being the a strong proponent of treating case on predicates like case on arguments, a goal I share throughout.

${ }^{2}$ Late GB Theory derived the requirement that argument NPs, but not predicates, needed case from the "Visibility Condition" given in (i):

(i) The Visibility Condition: A chain is visible only if it has a Case position Arguments must bear Case, and predicates may not bear Case....

A more exact description is given in den Dikken \& Næss (1993):

Arguments, bearers of thematic roles, must be made visible for the Theta Criterion through the assignment of a Case feature; predicates, on the other hand, do not impose this requirement, hence do not need Case. Economy considerations then dictate that predicates are not allowed to bear Case. (den Dikken \& Næss: 303-304)

I assume that elimination of such distinctions is a step forward in understanding the relation of morphology to syntax.

${ }^{3}$ This term is originally due to Wayles Browne, who related it exactly to avoid saying "agreement", which has acquired a new meaning since the advent of Minimalism, and which is misleading in its implication as to the right analysis of certain phenomena.

${ }^{4}$ Note that (23b) and trees throughout this article show verb raising to Pred ${ }^{0}$. This assumption is taken from Bowers, and parallels obligatory $\mathrm{V}$ raising to $v$ in Chomsky (1995). However, nothing crucial in the account follows from this raising. Not crucially that the verb does not raise as high as I in the overt syntax, as argued in Bailyn (1995).

"Here "lexical" refers to the lexically idiosyncratic nature of the case in question, and not to the nature of the category of the case assignor, which in the case of predicates is a functional head.

"At first glance it appears that we then predict "Sameness" nominals to end up in an LF position distinct from Instrumental Nominals. However, on the assumption that Agreement must also be checked on AP predicates, the Instrumentals presumably move at LF also, for independent reasons. Thus the LF positions of the different predicate types are not distinct.

${ }^{7}$ Double-layered specifiers are not generally allowed (or we would expect multiple occurrences of the same structural case regularly in language). I assume the general restriction against double-specifiers follows from the theta-criterion, stating that two theta-marked elements may not occupy the same structural position (at LF). If this is indeed the nature of the restriction on multiple specs, there appears to be no reason why the restriction should extend to predicates, which do not bear theta-roles. We would thus expect a predicate to be able to share specifierhood of a head with an argument, acquiring all of the same morphological characteristics by virtue of being in the checking domain of the same head. 
${ }^{8}$ The alternative Instrumental forms found in Russian and with Polish NPs do not share this meaning, and as such can be analyzed as small clause raising construction similar to what we have already seen, where the 'to be' element is indeed a verb taking a small clause complement.

${ }^{9}$ Another possibility for reducing this correlation to something morphological involves treating certain Pred 0 heads as "affixal". All overt morphology in Pred would require [+affixal] Pred to allow both the morphology and the formal features of Pred to occupy one head position. Primary $\operatorname{Pred}^{0}$, because they always raise to T, would also be affixal; (see 5.2) For now, I leave deeper explanation of the MPR to future research.

${ }^{10}$ This inverts the usual description of these facts, namely that jest licenses Instrumental on NPs and Nominative on APs, whereas to allows only Nominative. Rather, I propose to is unambiguously a head of Pred, taking NP complement and jest as Pred, takes only AP complements. jest also occurs as a raising verb, taking Instrumental complements. This predicts that Polish should allow some AP-instrumentals as well, which Przepiórkowski (2000) shows are possible, contra Bailyn \& Citko (1998). to, on the other hand, does not double as a verb, therefore to with Instrumental is always impossible -- it is always an overt predicator so it always absorbs case. 